\title{
A Case Study \\ Of Unintended Consequences Of Teams
}

Lawrence E. Zeff, (Email: zeffl@udmercy.edu), University of Detroit Mercy

Mary A. Higby, (Email: higbym@udmercy.edu), University of Detroit Mercy

\begin{abstract}
Teams have been widely proclaimed to be the panacea of corporations. Many teams have been very effective. And the role of organizational culture is critical in providing an appropriate supportive environment for fostering team performance. This paper presents a case study describing a successful and effective team development process and a modified organization culture consistent with and necessary for high team performance and member satisfaction. It describes three stages of interaction as a consequence of a clash of radically different cultures. This study highlights unintended social and political consequences a team development process had on non-team members in a broader organizational context.
\end{abstract}

\section{INTRODUCTION}

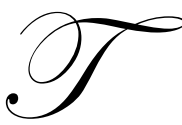

eam literature generally describes the positive impact that teams have on productivity, the conditions under which teams are successful and the factors which lead to team success and, in particular, crossfunctional team success. While the literature concentrates on these factors, it seems to avoid the negative factors of teams throughout the organization. One distinction between groups and teams is to precisely identify that true teams overcome some of the problems with groups. For example, the difficulties groups face with the Abilene paradox and social loafing may occur within the context of relatively independent, perhaps pooled, tasks. Teams, however, characteristically create interdependent tasks requiring members to work together with higher commitment toward jointly created goals, thereby eliminating the opportunity for and desire to reduce one's contribution toward the group output. This paper reports the findings of positive and negative social and political effects of team creation and development at a new subsidiary of an existing software engineering firm geared more toward customized e-business application development. While teams overcome many of the shortcomings found in groups, the present case study found the impact teams have on the broader organization may create additional difficulties.

\section{REVIEW OF THE LITERATURE}

In many organizations, teams have been implemented to enhance the organization's competitive advantage. According to Katzenbach and Smith (1993), "a team is a small number of people with complementary skills who are committed to a common purpose, set of performance goals, and approach for which they hold themselves mutually accountable." (p.112) Teams require individual and mutual accountability, and have a leadership role shared by team members (Katzenbach and Smith, 1993). Katz (1997) describes a high performing team as one that is empowered, self-directed, and cross-functional to have complementary skills. In addition, team members are committed to working together and achieving their agreed upon common goal. To accomplish this, they work collaboratively by respecting team members. This approach makes sense, since they have a perspective of shared accountability where many tasks require collaboration and jointly produced outputs. Teams have collective work products requiring joint contributions of members (Katzenbach and Smith, 1993). Teams can also perform at levels higher than typical work groups. (See, e.g., Burghard and Mackay, 2004; Majchrzak and Wang, 1996; Mulvey, Veiga and Elsass, 1996.) This higher performance level is the result of a synergy resulting from collaboration and jointly produced outputs rather than a pooling of individual outputs (Katz, 1997). More recently, Ancona, Bresman and Kaeufer (2002) have found that traditional teams are too inner-focused and lack flexibility. To overcome some of 
these problems, they recommend that teams must continue to engage in team building but also gain a greater awareness of their external stakeholders and information sources. In a study of 800 new product development projects, Akgun, Lynn and Byrne (2004) found that successful new product projects included experienced people who had been involved in previous new product programs, brought to the team information gained from previous assignments, worked in several different functional areas before working on this project and had managers who had worked on similar products within the company.

Several implications for creating an appropriate environment follow from these characteristics and conclusions. The team environment is similar to successful job enrichment. In the typical work environment a manager determines and plans the work of his/her subordinates and the jobs (tasks) are narrowly defined, whereas in the team environment the manager collaborates with subordinates as peers and team members jointly establish and plan the work. Thus, the skill set required is broad, potentially providing for individual growth and development. This development is often accomplished within the context of cross training and working directly with other team members. Moreover, this learning process is continuous and is part of the culture of the unit. Because joint accountability exists, people work together and rewards are based on both individual performance and the individual's contribution to the team's overall performance, while all members are directly involved in continuous improvement.

In many instances it is necessary to implement project or cross-functional teams where multiple functions are represented on a team. Project teams or cross-functional teams encourage information exchange, provide a degree of formalization and encourage cooperation. Cross-functional teams depend upon the collaborative contribution of each member of the team so that different perspectives and knowledge bases can be used to increase innovation and speed to market (Lovelace, Shapiro, \& Weingart, 2001; Griffin \& Hauser, 1997).

The key is a good set of technical skills, but it is not enough. They are important but not sufficient to determine high levels of effectiveness or success. For new product development teams, organizations typically try to create teams composed of those people who could contribute to a new product. For example, a team would include an engineer, a marketing person, production individual, etc. Each person is an individual who is highly skilled in his or her functional area. But as athletic teams have learned, a compilation of skilled players does not necessarily make a championship team. The term used in sports is chemistry. Interpersonal skills comprise the sports analogy of team chemistry and are the necessary components to allow for synergy. To gain the benefits of synergy, that is, where the whole is greater than the sum of the parts, people must willingly and openly share ideas, comments and criticism. Katz (1997) identifies effective communication as one of those characteristics usually associated with high performing teams. Thompson (2004) suggests that an effective team needs to have members with technical skills but also interpersonal, decision-making and problem-solving skills. Strozniak (2000) reports that people skills are where teams struggle, not with technical skills.

Another critical skill in determining success of teams, and often more critical for new product development teams, is the set of political skills. These skills include the ability to gain support from key areas outside of the team, to gain acceptance of the team's output, to gather required resources which allow the team to work towards its goal, and to protect the team against external threats and overcome obstacles in the team's path. Likewise, internal political skills are required of team members to confront and overcome conflict issues as they arise. An agreed upon conflict resolution process is necessary to provide opportunities for intra-team cooperation and high performance levels (Katz, 1997).

\section{CASE STUDY}

An on-going engineering company (parent company) purchased a small computer software firm (startup company). This startup was transformed into a new e-business venture and became a wholly owned subsidiary in the late 1990s. The CEO of the parent company was also the CEO of the startup company. The CEO's vision was to create an internet-based consulting company that would become the major revenue generator for the larger combined organization. The Chief Operating Officer of the subsidiary (COO) was a lawyer with computer skills who, along with the CEO, envisioned that the firm could provide myriad of solutions to any potential internet problem or opportunity a customer might identify. As such, the $\mathrm{COO}$ was charged with building several teams having the 
computer skills necessary to create potential modules for such possible opportunities. The startup company's COO was responsible for creating teams and encouraging them to build modules as a part of a potential product portfolio that would eventually be offered to customers. The parent company $\mathrm{COO}$ had a traditional engineering background and was responsible for overseeing multiple projects and maintaining positive customer relations. His focus was more external than internal. The CEO, coming from a marketing background, had little knowledge of or interest in the technical aspects of the engineering operations. He was, however, intrigued with and enthralled by the software applications being created in the startup company.

\section{Research Methodology}

Much of the data were gathered from discussions with both parent company and subsidiary personnel. Initial discussions were held with a group of managers from both organizations. These group discussions led to follow up meetings and interviews between one or both of the researchers and members of higher-level management from each organization. In addition, we were given access to documents, including the subsidiary's initial business plan and documents given to Wall Street investors when trying to obtain their IPO. After reviewing these documents and official organization charts, we had several additional meetings, which were necessary to understand the relationships between people. An interview protocol emerged from materials gathered after thirty hours of discussions with personnel from both the startup and parent companies. This protocol provided the framework for individual one-hour in-depth interviews with the COO's of the two companies and other top managers from the startup company. The startup company $\mathrm{COO}$ was directly responsible for team creation and development and the other key managers were responsible for organizational performance and ultimately integrating the startup company with parent organization personnel. All interviews were taped with the permission of the participants. The three basic areas covered in these final interviews included: (1) how these new product development teams were created, i.e., what was the basis for determining which specific people should be integrated into a particular team; (2) factors perceived to enhance the likelihood of team effectiveness, that is, elements in the organizational culture or criteria for team creation that might have increased the probability of success for the team; and, (3) factors that were considered to have inhibited the likelihood of team effectiveness, that is, conditions which existed that may have led to the failure or lack of success of one or more teams.

We evaluated our notes from all meetings and reviewed the taped interviews. Data collected here provided a comprehensive picture of events as they unfolded during this timeframe. Where discrepancies were noted, particularly between the perceptions of the two COOs, the dominant view from all sources was taken to be the more accurate description of what really happened. However, since people act on the basis of their own perceptions, we found these differing views to be very helpful in describing and explaining each organization's use of work groups. These multiple sources of data reduce the bias that accrues from interpretation of any one source of information. Results, therefore, are more powerful and valid as suggested by Flick (1992) in his discussion of triangulations.

\section{Team Creation and Development in the Startup Company}

Initially, the startup company was in a separate facility thirty miles away from parent company offices. The subsidiary's COO hired a set of people from other companies in the field. As each person was hired and brought on board, they were integrated into a developing culture based on collaboration and teamwork. A lot of time was spent establishing a team esprit de corps. The COO spent considerable effort towards creating a highly supportive, teamoriented organizational environment. Each new team member was highly creative and encouraged to apply their creativity to work-related tasks. These employees were willing and almost desiring to work long hours. The atmosphere was almost playful and teams became highly cohesive. People actually looked forward to coming to work and facing the challenges they encountered.

Cross-functional teams were formed to complete software modules of an internet-based product and work on-site with specific clients. Their clients rated performance levels very high including the dimensions of quality of work, speed with which software packages were developed and satisfaction of on-site work. The COO was very concerned that team members be fully integrated and that cohesiveness be high. For example, one way of integrating non-native English speakers into the team environment was to use the foreign language skills of other members of the 
startup company. So, French Canadians were brought into a team where several members were fluent in French, making the transition to this company more fluid and effective. The $\mathrm{COO}$ established a strong decentralized decision making process consistent with his leadership style and the culture being developed during this time. Each new product development team was allowed to and, in fact, was responsible for establishing its own goals and distributing tasks required to accomplish goals within the larger framework of the startup company's mission. These crossfunctional teams, therefore, were able to develop beyond being just groups by becoming true teams as Katzenbach and Smith (1993) define them. All ingredients necessary for team creation and development were in place at the startup company. These ingredients included: a natural decentralization that allowed for team goal setting and decisionmaking; a strong sense of identity encouraged by the team environment; ongoing encouragement and support from the COO; and, the nature of interdependent client-centered work requirements (Mintzberg, 1979; Fredrickson, 1986).

New product development teams were comprised of five individuals, each with a critical skill necessary to accomplish prescribed tasks and work on client-based problems. Four people had skill sets necessary for the new product development team to function in its day-to-day activities and were, therefore, permanent members of the team. This was true even as projects were completed and new tasks were assigned. The fifth person had a skill set critical for task accomplishment and ultimate goal attainment but was not necessary on a day-to-day basis. As a result, this fifth person had multiple memberships on two separate new product development teams. People had a strong commitment both toward their teams and to the startup company as a whole. The organizational culture encouraged this dual perspective and overriding cooperative environment.

The COO was aware that technical skills were not enough to create a team. He was very conscious of personality, interpersonal relations and political skills in forming highly cohesive teams. His view suggested that failure to account for these non-technical attributes would be a major inhibitor to team effectiveness. This concern for creating highly cohesive teams underscored his actions.

The first year saw four sets of individuals formed into groups and molded into true cross-functional teams and, as much of the literature suggests about the positive impact of teams, performance levels were very high (Anacona, Bresman \& Kaeufer, 2002; Griffin \& Hauser, 1997). Not only was client satisfaction high with team output, individual work satisfaction internally was also high. With high morale came high commitment to company and team processes. High cohesiveness and on-going social interaction also resulted in commitment to other team members. The company mission was integrated into daily routines and the CEO was delighted with the subsidiary's overall initial accomplishments.

\section{Differences in Work Processes}

Organizational use of work groups at the parent company reflected the engineering partners' concern for technical expertise, engineering task completion and a sense of professionalism toward their clients. These work groups rather than teams continued until the project was completed. Membership for each work group was determined by the Chief Operating Officer (COO) of the parent-company. There was no attempt to develop group members into a team, nor was there any training in group dynamics or team building. While membership was permanent relative to the specific project, over time group membership was temporary. Often, in completing these projects, clients or the project itself placed severe time pressures on parent company group members. The norm was to accept and readily work under these time pressures. Staying late, for example, to complete a necessary step was expected, encouraged and readily accepted into employees' behavior patterns. Cordial interpersonal relations developed in the office, but tended to be kept on a strictly job-related level with little socialization taking place outside of the workplace. So their perception was a friendly work environment of hard working highly skilled professionals who tended not to joke around or to socialize beyond the confines of their work experience. It was a pleasant but strictly work-oriented organization. Moreover, there was a real sense of hierarchy and people adhered to the internal pecking order. As a result group leadership was based on the hierarchy and assigned managerial roles rather than emerging from within the work group.

In contrast, team membership in the startup company was permanent rather than tied to a specific project. The intent here was to take a long-term perspective and work toward creating many new software products and solve 
problems for many clients. Hierarchy at the startup company was not a factor in identifying team or project leaders nor did the COO play a direct role in appointing team leadership. Rather, his decentralized decision making process allowed the teams to develop, identify and select team and/ or specific project leaders. As indicated earlier, startup company personnel seemed to enjoy working late. It apparently did not matter to team members whether they were socializing on the job or off of the job. They were going to socialize anyway. Staying late, therefore, may not have been tied exclusively to task completion. They were working on modules for which no client as of yet existed. Time pressures were not that critical. They choose to stay late and work together.

One more difference, the $\mathrm{COO}$ of the parent company selected group members on the basis of skills required for a particular project. Personality, political skills, or other non-technical factors were not considered in this selection process instead, availability and technical skills were the sole determinants in making selections. This seems to suggest that factors which might inhibit group effectiveness were not part of the decision making process. This is consistent with the perceptions that completing the task or project and having exclusively a professional work environment pervaded all behaviors and decisions. At the opposite extreme is the care with which the $\mathrm{COO}$ of the startup company determined team membership. Technical skills were certainly important but there was an overriding concern to create a highly cohesive, highly cooperative team. Apparently, the startup company COO was very cognizant of factors that enhanced the likelihood of team effectiveness.

\section{Unintended Consequences}

When the startup company was merged into parent company operations, the effects of these differences in work processes became apparent. The parent company was working in a desired state of equilibrium. People knew what the expectations were and they performed up to those expectations. The introduction of the startup company's team-oriented work processes disrupted parent company operations. These engineers did not know to respond to this team-oriented approach to work. They questioned the technical abilities of the programmers but were curious about the socializing aspect seen in startup company teams. Moreover, they were somewhat puzzled by the lack of importance of organizational hierarchy as a source for team leadership. This disequilibrium was uncomfortable, at times unnerving, to both parent and startup company members.

Initial work performance fell for both organizations. Yet people in each organization believed they were superior to their counterparts, although along different dimensions. Parent company personnel believed they were technically superior as they felt they could be project leaders with programmers as project group members. They felt strongly, however, programmers could not be project leaders with engineers as subordinates. Programmers, on the other hand, suggested that they were indeed the superior set but supported this claim along political rather than technical dimensions.

As of the end of our interviews, the combined organization was moving toward, but had not yet reached, a new equilibrium. In addition, overall performance levels were improving but had not yet attained the level of performance seen before the organizations were joined together. The disruption of parent company's equilibrium pattern has left emotional, technical and political scars on all people involved. Reaching a new equilibrium has taken much more time and effort than anybody had imagined. These unintended consequences have been quite significant in spite of the initial positive teams and the team environment had on startup company performance. It is unclear at this point whether the overall team impact on corporate personnel will be positive or negative. What is clear, however, there are negative consequences of team creation and development.

The positive impact of team creation and development on the small startup company dissipated when this subset (the startup company) began interacting with a larger corporate-wide environment. No consideration was by the CEO was given to these potential unintended consequences. No political concerns were included in the preparation for absorbing the startup company by the parent company. Even the COO of the startup company did not try to caution the CEO about any non-technical dimension that might affect overall performance. 


\section{CONCLUSIONS AND IMPLICATIONS}

Interviews for this study revolved around three basic questions. he first question related to how new product development teams were created. This study underscores the importance of understanding more than just technical requirements of teams. Parent company groups were formed on the basis of technical expertise and availability. There was no desire or opportunity for these groups to develop into true teams. Startup company teams, however, were formed within the context of a true team environment. As Katz's (1997) Alpha Chip example suggests, other dimensions, for example, political and social, are as important as the technical dimension alone.

Factors perceived to enhance the likelihood of team effectiveness found in this study also reflect what much of the literature suggests. Camaraderie enhanced by socializing (in this case both on and off of the job) allowing teams to determine its own leadership, team as well as individual accountability, and environment supportive of team development all enhance the likelihood of team effectiveness. In addition, ensuring the team has all of the technical, political and social skill sets required for successful task completion was also found to be critical here.

But it is the third area that led to unintended consequences reported above. Factors that inhibited team effectiveness went beyond the specific teams of the startup company. For a team to be successful as the responses to the second question indicate requires an environment supportive of teams. That is, creating a successful team automatically creates a team environment or subculture. This subculture must of necessity clash with the larger organizational culture unless the entire organization is based on and operates within a strong environment. Since this is not often likely to occur, team creation carries with it a strong potential for these unintended consequences. Perhaps the major unintended consequence of teams, therefore, is culture clash between the team environment and the organizational culture as a whole.

While much of the research has reported team impact on productivity basically by looking at teams as the unit of analysis, taking a broader perspective, as shown in this case study, indicates a more far ranging impact on the larger organization. Specifically, the political and social dimensions indicate care must be taken beyond just the establishment of cross-functional new product development teams. The cross-functional nature has a real positive impact on team productivity. High team cohesiveness also seems to have a positive impact on productivity as team members help establish and gain high commitment toward team output goals. As noticed in previous reports, for example, Katz's (1997) Alpha Chip, and this case study reported here, a broader external perspective might interpret this same cohesiveness in a negative light when taken from the perspective of outsiders. In addition, most of the research has taken a relatively short-term view of team performance without considering what happens beyond project completion. For example, there is often a let down after team projects are completed (Thompson, 2004). The ramifications may include a negative impact on project completion as people strive to keep a particular team together (Thompson, 2004).

\section{REFERENCES}

1. Akgun, A. E., Lynn, G.S., \& Byrne, J. C. 2004. Taking the guesswork out of new product development: How successful high-tech companies get that way. Journal of Business Strategy, 25 (4) 41-46.

2. Alexander, J. D. 1990. Analytic debates: Understanding the relative autonomy of culture. In J.C. Alexander \& S. Seidman (Eds.), Culture and society: Contemporary debates: 1-27. Cambridge: Cambridge University Press.

3. Ancona, D., Bresman, H. \& Kaeufer, K. 2002. The comparative advantage of X-teams. MIT Sloan Management Review, 43 (3): 33-30.

4. $\quad$ Burghard, E. \& Mackay, L. 2004. Team spirit. Marketing Management, 13 (6): 18-20.

5. Flick, U. (1992). Triangulation revisited: Strategy of or alternative to validation of qualitative data. Journal for the Theory of Social Behavior, 22, 175-97.

6. Fredrickson, J. (1986). The strategic decision process and organizational structure. Academy of Management Review, 3 (July), 280-289. 
7. Griffin, A. \& Hauser, J. (1996). Integrating R\&D and marketing: A review and analysis of the literature. Journal of Product Innovation Management, 13 (6) 478-496.

8. Hofstede, G., Neuijen, B., Ohayv, D. D., \& Sander, G. (1990). Measuring organizational cultures: A qualitative and quantitative study across twenty cases. Administrative Science Quarterly, 35: 286-316.

9. Katz, P. (1997). How a team at Digital Equipment designed the 'Alpha' Chip. In R. Katz (Ed.), The human side of managing technological innovation (137-148). New York: Oxford University Press.

10. Katzenbach, J. R. \& Smith, D. K. (1993). The discipline of teams. Harvard Business Review, 71 (MarchApril), 111-146.

11. Lovelace, K., Shapiro, D. L., \& Weingart, L.R. (2001). Maximizing cross-functional new product teams' innovativeness and constraint adherence: A conflict communications perspective. Academy of Management Journal, 44: 779-793.

12. Majchrzak, A. \& Wang, Q. (1996). Breaking the functional mind-set in process organizations. Harvard Business Review, 74 (September-October), 93-99.

13. Mintzberg, H. (1979). The structuring of organizations. Upper Saddle River, NJ: Prentice-Hall.

14. Mulvay, P. W., Veiga, J. F., \& Elsass, P. M. (1996). When teammates raise a white flag. Academy of Management Executive, 10 (1), 55-64

15. Randel, A. E. \& Jaussi, K. S. (2003). Functional background identity, diversity and individual performance in cross-functional teams. Academy of Management Journal, 46 (6), 763-775.

16. Schein, E. H. (1992). Organizational culture and leadership. San Francisco: Jossey-Bass.

17. Schein, E.H. (1999). The corporate culture. San Francisco: Jossey-Bass.

18. Smircich, L. (1983). Concepts of culture and organizational analysis. Administrative Science Quarterly, 28: 339-358.

19. Strozniak, P. (2000). Teams at work: Team culture at small manufacturers. Industry Week, (September 18), 47-50.

20. Thompson, L.L. (2004). Making the team. Upper Saddle River, NJ: Prentice-Hall.

\section{NOTES}




\section{NOTES}

